\title{
Percepções dos alunos acerca da diversidade étnico-racial no currículo do Ensino Técnico Integrado ao Médio
}

Augusto Rodrigues de Sousa* Lediane Fani Felzke**

\begin{abstract}
Resumo:
Esse artigo apresenta os resultados de três rodas de conversa realizadas com alunos do ensino técnico integrado ao médio do Instituto Federal de Rondônia (IFRO), campus Porto Velho Calama, nas quais foram discutidas as percepções dos alunos acerca das temáticas referentes às relações étnico-raciais. A metodologia proposta é de natureza qualitativa e caráter exploratório e participante, a partir de uma percepção decolonial e afrocentrada dos processos de produção do conhecimento. Como resultados de nossas análises constatamos que os alunos consideram importante o trabalho em torno das referidas temáticas, reconhecem o processo de apagamento que ainda se mantém acerca das mesmas e propõem possibilidades pedagógicas integradas voltadas para a interdisciplinaridade.
\end{abstract}

\section{Palavras- Chave:}

Lei 10.639/2003. Ensino Médio Integrado. Interdisciplinaridade.

\begin{abstract}
:
This article presents the results of three conversations held with students of technical education integrated to the medium of the Federal Institute of Rondônia (IFRO), campus Porto Velho Calama, in which they were discussed as students' perceptions about the themes related to ethnic-racial relations. For the methodological screening, a qualitative, exploratory and participative research was chosen, based on a decolonial and afrocentric perception of knowledge production processes. As a result of our research students consider the work around the themes to be important, recognize the erasure process that still remains on them and propose integrated pedagogical possibilities aimed at interdisciplinarity.
\end{abstract}

\section{Keywords:}

Law 10.639/2003. Integrated High School. Interdisciplinarity.

\footnotetext{
* Mestre em Educação Profissional pelo Programa de Mestrado Profissional em Educação Profissional e Tecnológica do Instituto Federal de Educação e Ciências de Rondônia (ProfEPT/IFRO). E-mail: augustosdb@gmail.com. ORCID iD: http://orcid. org/0000-0003-4647-5397.

** Doutora em Antropologia Social. Professora EBBT do Instituto Federal de Rondônia, campus Ji-Paraná. E-mail: lediane.fani@ ifro.edu.br. ORCID iD: http://orcid.org/0000-0002-5367-1209.
} 


\section{Introdução}

O presente artigo apresenta o recorte de uma pesquisa de mestrado concluída, vinculada ao Programa de Mestrado Profissional em Educação Profissional e Tecnológica (ProfEPT) e realizada no Instituto Federal de Rondônia (IFRO), campus Porto Velho Calama. Nosso objetivo é o de contribuir para a implementação da consideração pela diversidade étnico-racial no contexto da Educação Profissional e Tecnológica, a partir do reconhecimento da voz dos próprios estudantes, rompendo, dessa maneira, com os esquemas hegemônicos que não reconhecem no aluno um sujeito participante do processo de construção do conhecimento. Nesse sentido, o artigo apresenta as percepções de 15 alunas e alunos do Ensino Técnico Integrado ao Médio acerca da importância e das possibilidades de ensino das relações étnico-raciais.

Proposto a partir do Decreto ${ }^{\circ}$ 5.154/2004, o Ensino Técnico Integrado ao Médio (ou Ensino Médio Integrado) trata-se de um modalidade de ensino que atualmente tem se consolidado como a principal forma de oferta de educação profissionalizante no país, sendo realizado em diferentes sistemas, tais como Centros Federais de Educação Tecnológica (CEFETs), Institutos Federais (IFs) e algumas redes estaduais de ensino. Seu objetivo é integrar a formação básica e a Educação Profissional através da matrícula única em vistas do imediato acesso ao mundo do trabalho (SILVA; OLIVEIRA, 2018).

No âmbito específico das instituições da Rede Federal de Educação Profissional, Científica e Tecnológica têm-se buscado que os cursos oferecidos para o Ensino Médio sejam preferencialmente segundo essa modalidade. Entretanto, os dispositivos legais permitem também as modalidades "concomitante", oferecida em matrícula distinta para quem está cursando o Ensino Médio, podendo ser realizado em instituições diferentes de ensino; e "subsequente", isto é, formação técnica voltada para pessoas que já concluíram o Ensino Médio.

Apesar disso, alguns desafios ainda se impõem à plena implementação dos currículos integrados, dentre os quais pode-se destacar a necessidade de formação específica dos educadores nessa modalidade (desafio ao qual o ProfEPT, dentre outras iniciativas visa superar) e a forte tendência ao conteudismo e à divisão disciplinar dos currículos, dentre outros aspectos. Esses desafios levam ao risco, por exemplo, de simplesmente se sobrepor as disciplinas propedêuticas e técnicas, o que não se configura com os objetivos de tal modalidade, voltada muito mais para a formação integral, omnilateral e politécnica dos alunos (FRIGOTTO; CIAVATTA; RAMOS, 2005).

A implantação dos currículos integrados em si já se apresenta como um grande desafio que se propõe às instituições que trabalham com a EPT para os próximos anos, entretanto, outros desafios educacionais coexistem e exigem atenção simultânea, dentre os quais pode-se destacar a questão da consideração pela diversidade étnico-racial brasileira, também definida por meio de instrumentos legais.

A partir da Lei $n^{\circ} 10.639 / 2003$, posteriormente ampliada pela Lei $n^{\circ} 11.645 / 2008$, tornou-se obrigatório o ensino de história e cultura africana, afro-brasileira e indígena em todos os níveis de ensino da Educação Básica no Brasil. Tais leis são o resultado dos esforços dos movimentos negro e indígenas pelo reconhecimento da participação fundamental dessas populações na formação da sociedade brasileira, bem como se configuram como importantes políticas de reparação diante do racismo estrutural que baseia as relações sociais no país.

Apesar disso, o contato com o cotidiano escolar infelizmente nos demonstra que ainda persistem muitas resistências por parte dos atores sociais envolvidos nos processos educativos em implementar o arranjo legal que, há quase vinte anos, propõe a abertura dos currículos à diversidade racial. Essas resistências decorrem de diversos fatores, em especial pela ausência de investimentos na formação dos profissionais em Educação sobre essas temáticas, a deficiência de materiais didáticos com essa perspectiva de ensino; e, não se pode deixar de mencionar, por muitas intolerâncias e preconceitos enraizados na sociedade brasileira.

Segundo Almeida (2018), o racismo não se trata de um fenômeno ligado apenas a escolhas morais individuais, mas, é sempre estrutural, especialmente em uma sociedade formada a partir da colonização e da escravidão. Ou seja, o racismo, ainda que se materialize em discriminação racial, transcende a ação 
individual, caracterizando-se como um processo em que as condições de subalternidade e privilégios são distribuídas entre os grupos sociais e reproduzidas nos âmbitos políticos, econômicos e das relações cotidianas.

Por conseguinte, como as instituições reproduzem e materializam as estruturas da ordem social em práticas cotidianas concretas, também a escola se constrói como espaço em que o racismo está presente institucionalmente, como materialização do modo de socialidade que tem o racismo como um de seus componentes orgânicos. Dessa forma, o racismo presente no cotidiano da ordem social por ser o comportamento "normal" reconhecido e replicado através de práticas sociais de violência explícita ou microagressões, como piadas, silenciamentos e isolamento e, principalmente, pelo apagamento da história e da cultura de negros e indígenas, através de um currículo majoritariamente eurocêntrico.

As políticas afirmativas reconhecem explicitamente o desafio do racismo, aparentemente invisível porque naturalizado; e, através da valorização de outras fontes de conhecimento, visam ampliar as possibilidades de percepção da realidade a partir das heranças africanas, afro-brasileiras e indígenas, construir novas relações raciais possíveis, promover processos de aprendizado coletivo e, principalmente, reparar dos danos psicológicos, materiais, sociais e educativos que as populações negras e indígenas têm vivenciado (BRASIL, 2004).

Nesse sentido, a tradição filosófica do feminismo negro ensina sobre a importância de nomear as opressões, "já que não se pode combater o que não tem nome" (RIBEIRO, 2019, p. 21). Assim, o combate ao racismo exige reconhecê-lo e desenvolver práticas explícitas para sua superação ${ }^{1}$, ao mesmo tempo em que convida a considerar a importância da história dessas populações não apenas a partir do viés do sofrimento, mas da riqueza dos seus percursos de produção do conhecimento, das possibilidades de socialidades alternativas que propõem, da resistência e da luta para manter seus modos de vida, dentre outros aspectos.

É importante salientar que as políticas afirmativas não se limitam à inserção de temas e conteúdos no currículo escolar, mas também na ampliação de oportunidades de acesso das populações negras e indígenas aos espaços materiais de produção do conhecimento, isto é, a docência, o acesso à universidade, aos cursos profissionalizantes e às propostas de currículo integrado na Educação Básica. Para Arroyo (2012) a maior presença desses sujeitos sociais nos espaços educativos interroga as pedagogias tradicionais, promotoras do silenciamento de outras epistemologias e guardiãs de uma exclusividade pedagógica que se interpreta como única alternativa; e exigem a emergência de outras pedagogias, pautadas na escuta das vozes dos próprios sujeitos.

Ao se considerar o horizonte politécnico que se delineia como meta da implementação dos currículos integrados no Brasil e recordar como o conceito de politecnia é assumido como possibilidade de emancipação da classe trabalhadora, encontramos nele a possibilidade de diálogo com outros caminhos epistemológicos, especialmente as de tradição afrocentrada e decolonial, como chance de se estabelecer pontes entre os desafios de implementação dos currículos integrados e da consideração pela diversidade étnico-racial num único movimento educativo de caráter emancipatório (FRIGOTTO; CIAVATTA; RAMOS, 2005).

De fato, a herança das tradições decoloniais latino-americanas e do feminismo negro, que nos apresenta o conceito de interseccionalidade, revelam que o sistema-mundo vigente não se baseia apenas nas relações de classe impostas pelo capitalismo, mas que se sustenta numa trama de relações que raça, gênero e classe de tal modo que a emancipação plena da pessoa perpasse todas as essas dimensões. Por isso é plenamente possível, e necessário, pautar a prática politécnica também em processos explicitamente antirracistas (MALDONADO-TORRES, 2010; DAVIS, 2016).

Uma possibilidade de começar esse diálogo foi partir das percepções dos alunos acerca da pertinência das temáticas raciais no contexto do Ensino Técnico Integrado ao Médio. É nesse sentido que nos propomos a realizar as rodas de conversa das quais apresentamos aqui os resultados e a análise de como considerações dialogam, questionam ou enriquecem a reflexão pedagógica acerca do tema.

1. É bastante conhecida a frase atribuída a Ângela Davis, citada em diversas produções acerca das relações étnico-raciais e políticas públicas antirracistas: "Em uma sociedade racista, não basta não ser racista, é preciso ser antirracista". 


\section{Metodologia}

As rodas de conversa inserem-se entre as possibilidades metodológicas de natureza qualitativa e de caráter exploratório e participativo que permitem a construção coletiva do conhecimento a partir de um processo de comunicação dinâmico e produtivo. De fato, proporcionam tanto a produção de dados quanto se constituem como espaços de aprendizagem. Sendo, dessa forma, uma possibilidade metodológica que funciona como elo entre a pesquisa e os processos de ensino-aprendizagem (MELO; CRUZ, 2014; MOURA; LIMA, 2014).

Ao mesmo tempo, por nos situarmos teoricamente a partir de um lugar decolonial e afrocêntrico numa chave de leitura politécnica, vemos nessa metodologia traços do valor afrocivilizatório da circularidade, paradigma de mundo e de relações humanas presentes nas culturas africanas, afro-brasileiras e indígenas. Esse valor se materializa em espaços e momentos de convivência, tais como rodas de capoeira e de samba, no formato das casas indígenas, nas conversas ao redor da fogueira dos povoados, dentre outros (SOUSA; FELZKE; OLIVEIRA, 2019).

A circularidade, compreendida como valor civilizatório, remete à inclusão, à interação igualitária e cooperativa e ao movimento natural do cosmos. Dessa forma, quando vivenciado em momentos como as rodas de conversa produzem no próprio exercício o aprendizado de relações étnico-raciais que superem o mundo hierarquizado imposto pela lógica do sistema-mundo capitalista/colonial/patriarcal/moderno vigente.

Dessa forma, foram realizadas três rodas de conversas com 15 alunas e alunos do Ensino Técnico Integrado ao Médio do Instituto Federal de Rondônia, campus Calama, tendo como espaço de realização uma sala de aulas da própria instituição. As conversas foram realizadas fora do horário escolar, para garantir a liberdade e a tranquilidade dos alunos e foram filmadas com prévia autorização dos mesmos e de seus responsáveis. Ao mesmo tempo, a síntese das discussões era sempre compilada em um material textual, permitindo a posterior análise do material.

A análise, como apresentada a seguir, consistiu no confronto das percepções partilhadas nas rodas de conversa com reflexões sobre o racismo e a valorização da diversidade étnicorracial na literatura apresentada. Não sendo realizados procedimentos de análise de discurso ou conversação específicos, especialmente porque os próprios alunos de algum modo conduziram os processos vivenciados, de modo que nos permitiu focar tão somente no que foi dito e partilhado, sem posteriores interpretações subtextuais.

$\mathrm{O}$ ambiente onde foram realizadas as rodas de conversa era organizado de forma que as alunas e os alunos se sentissem à vontade. Da mesma forma, as dinâmicas propostas buscavam propiciar um espaço de familiaridade, confiança e protagonismo, no qual fosse possível discutir coletivamente o problema e os objetivos de pesquisa e decidir o produto educacional a ser elaborado. Todas as rodas de conversa partiam da leitura de um texto formativo, conforme detalhado nos resultados e discussão expostos a seguir.

De modo concreto, a estrutura das rodas de conversas propostas seguiu os procedimentos: a) organização da sala em círculo, permitindo a participação e o envolvimento de todos; b) motivação inicial do professor-pesquisador; c) primeiros diálogos espontâneos; d) confronto com materiais didáticos (textos, imagens, documentos, etc.); e) segundo rodada de partilhas pessoais, a partir das leituras e discussões anteriores; f) leitura do relatório da discussão e aprovação por parte de todas e todos.

\section{Resultados e discussão}

Na primeira roda de conversa foram discutidos quais temas os alunos consideram importantes de serem trabalhados em sua formação e se a discussão acerca do racismo poderia ser trabalhada entre eles. Além das disciplinas específicas da formação profissional, as alunas e alunos unanimamente afirmaram a importância do estudo das disciplinas de humanidades, especialmente de filosofia, no ensino técnico integrado ao médio; acentuando que elas contribuem para o amadurecimento do aluno em todas as dimensões humanas e não apenas nas habilidades técnicas. Entretanto, salientaram que o número excessivo de 
disciplinas isoladas muitas vezes não permite o aprofundamento nas temas e conteúdos trabalhados e que o formato das provas muitas vezes exige somente a memorização dos conteúdos.

Ao abordarem os temas que poderiam ser trabalhados, ressaltaram que preferem debater temas relacionados às inquietações do próprio cotidiano, como projeto de vida, educação financeira, educação emocional e afetiva, comportamentos práticos no ambiente de trabalho, dentre outros. Inicialmente, não abordaram espontaneamente nenhuma temática referente às relações étnico-raciais.

Motivados pelo pesquisador a debater sobre o tema do racismo e da diversidade racial, apenas metade do grupo considerou-o relevante para o trabalho em sala de aula, outra parte acreditava que o tema não era tão pertinente e que, mesmo que houvesse racismo no Brasil, não seria algo muito explícito. A partir disso, o grupo foi convidado a ler o texto "Desigualdades Raciais por Cor e Raça no Brasil" (IBGE, 2019) e o capítulo "Falar sobre racismo reverso é como acreditar em unicórnios" (RIBEIRO, 2018). Após a leitura, o grupo todo concordou que a temática das relações étnico raciais é um assunto importante a ser considerado.

A fala inicial dos alunos que minorizavam a pertinência desta temática reflete $\mathrm{o}$ apagamento e normalização do racismo como desafio para a sociedade brasileira. Ao mesmo tempo, a mudança de opinião diante da leitura de dados e conceituações sobre o racismo, propostas pelos textos, confirma a reflexão herdada do feminismo negro, explícitada por Ribeiro (2019), de que é preciso nomear explicitamente os problemas sociais, retirando-os do apagamento proposital das pautas, para que possam ser enfrentados. No caso do racismo e das relações étnico-raciais, parte do grupo não acreditava serem temáticas pertinentes não porque duvidassem de sua existência, mas porque nunca foram nomeadas explicitamente.

A crítica feita pelos alunos sobre a quantidade de disciplinas demonstra ao mesmo tempo que a proposta de integração curricular entre o ensino técnico e a formação básica do Ensino Médio tem sido realizado sob um formato de sobreposição de disciplinas e não de integração real das propostas educativas vivenciadas.

De acordo com Moraes e Küller (2016) a integração curricular se aprensenta como um desafio por conta do próprio modelo epistemológico ocidental hegemônico, que fragmenta a realidade para melhor compreendê-la e, por isso, assume uma concepção do conhecimento de modo fracionado e o processo de ensino-aprendizagem como a memorização de pequenas doses da cultura oficial. Dessa forma, há uma profunda relação entre a ideia de integração e a assunção de uma opção política claramente decolonial.

É interessante notar que os alunos tem consciência dos processos educativos que vivenciam e apresentam uma clara posição crítica aos modelos de sobreposição de disciplinas apresentados como ensino integrado, ao mesmo tempo em que afirmam claramente preferir processos educativos organizados em torno de temas geradores e que permitam o diálogo entre as diferentes disciplinas, inclusive com possibilidade de trabalho integrado entre elas, bem como nos processos avaliativos.

Essas percepções demonstram como, na verdade, a ênfase por processos educativos mais participativos e centrados no protagonismo dos alunos não se trata tão somente de um modismo, criado por alguns educadores e intelectuais, mas de uma exigência dos modos de socialidade que vivemos e do mundo do trabalho que se apresenta aos olhos dessa geração de jovens.

Certamente existem muitos desafios que se apresentam à Educação no Brasil e corremos o risco de pensar que devemos pensar em um por vez. Um discurso que se repete em alguns ambientes em que se diz "primeiro derrubar o capitalismo, depois as outras formas de opressão". A herança decolonial e do feminismo negro nos ensinam que a vida é um complexo e que todos os desafios estão entrelaçados (ou interseccionados), de modo que só podem ser superados vistos em conjunto (DAVIS, 2016). As conversas dos alunos demonstram que eles também pensam assim e por isso escutá-los pode nos ajudar a pensar processos educativos cada vez mais inclusivos, participativos, politécnicos e antirracistas.

$\mathrm{Na}$ segunda roda de conversa os alunos foram divididos em grupos para a realização de uma atividade de pesquisa nos livros didáticos da disciplina de filosofia, disponíveis para o uso dos alunos no triênio vigente, conforme escolha do IFRO-Calama no acervo do Programa Nacional do Livro Didático (PNLD) (2018-2020). Foi escolhida a disciplina de Filosofia pelo fato de o professor pesquisador ser dessa área, mas o mesmo exercício poderia ter sido realizado com livros de outras disciplinas. A atividade consistiu em folhear os livros e anotar as pensadoras e pensadores africanos e indígenas citados ou temáticas referentes 
às relações étnico-raciais. Foram analisadas as obras: Fundamentos de filosofia (COTRIM; FERNANDES, 2016), Filosofando: introdução à filosofia (ARANHA, 2016), Filosofia: experiência do pensamento (GALLO, 2014) e Convite à Filosofia (CHAUÍ, 2010). Enquanto os alunos analisavam os livros didáticos, o professor-pesquisador analisava os planos de aula da disciplina de Filosofia no Ensino Técnico Integrado ao Médio do ano de 2018, solicitados na Diretoria de Ensino da instituição.

Foi constatado que, de modo geral, nenhum dos livros didáticos analisados apresenta a reflexão filosófica de pensadoras e pensadores negros ou indígenas. Os quatro livros defendem a teoria hegemônica do nascimento grego da Filosofia por conta de certa capacidade dos gregos, adquirida historicamente, para a abstração do conhecimento, enquanto os demais povos seriam mais práticos, inclusive no desenvolvimento de conhecimentos matemáticos, astronômicos, etc.

De acordo com Noguera (2014), diversos são os argumentos utilizados para corroborar a tese do nascimento grego da Filosofia e de sua continuidade como pensamento exclusivamente universal, entre elas, a de que os gregos romperam definitivamente com a mitologia em suas reflexões filosóficas. A simples leitura dos diálogos de Platão ou de textos de filosofia medieval de Agostinho, no entanto, demonstram o contrário, pois ambos se utilizam abundantemente de mitos e mesmo de crenças religiosas em sua proposta filosófica.

Voltando à análise dos materiais didáticos, dois filósofos africanos são citados, Agostinho de Hipona e Hipatia de Alexandria. Apenas Agostinho é citado nas quatro obras, mas a ilustração do personagem apresenta um homem com traços europeus. Figuras de negros e indígenas são apresentadas nas quatro obras apenas como ilustração à temática principal do capítulo em que se encontram.

Nos planos de aula da disciplina de Filosofia analisados, não há menção à temáticas filosóficas africanas ou decoloniais. Repete-se a figura de Agostinho como único filósofo africano estudado, sendo que este filosófo foi assumido e embranquecido pelo ocidente por conta de sua perspectiva platônica e cristã de produção filosófica.

O resultado dessa análise ajudou os alunos a compreender melhor como se dá o apagamento de personalidades não ocidentais da produção oficial do conhecimento, bem como a depreciação da produção filosófica dos demais povos pela teoria do nascimento grego da Filosofia (epistemicídio). Nota-se ainda que o livro didático materializa a ideologia do embranquecimento que associa a humanidade, a cidadania e as grandes elaborações teóricas do pensamento humano aos brancos, enquanto negros e indígenas são apresentados caricaturalmente ou apenas como ilustração das teorias desenvolvidas pelos personagens brancos (SILVA, 2005).

Essa observação é relavante quando lida à luz de Fanon (2008), que demonstra como a contínua representação depreciativa, ou mesmo a não representação do negro, considerado o diferente, o outro, $o$ anormal, geram sentimentos de auto-rejeição e alienação da identificação de si mesmo com suas características físicas e suas origens culturais. Daí se compreende a necessidade e a importância de descontrução de estereótipos racistas e de visibilidade de pessoas e conhecimentos negros e indígenas como caminho de representatividade.

Da mesma forma, dialogando com as reflexões de Abdias Nascimento (2019), o embraquecimento da cultura também se configura como parte do processo de genocídio e apagamento da população negra historicamente realizado no Brasil. A ausência de autores negros nesses materiais não reflete de modo algum sua não existência nos espaços formais e informais de produção do conhecimento, eles existem; mas reflete o apagamento dos sujeitos e conhecimentos não eurocentrados ainda vigentes no espaço escolar.

Certamente os autores dos livros didáticos não tinham intenção explícita de praticarem o epistemicídio e racismo, entretanto, como afirma Almeida (2018, p. 52), por ser parte da estrutura social, o racismo não precisa de uma intenção explícita para se realizar, de modo que, o simples silêncio, ainda que "não faça o indivíduo moral e/ou juricamente culpado ou responsável, certamente [...] o torna ética e politicamente responsável pela manutenção do racismo". Desse modo, a mensagem implícita que os livros acabam por apresentar é a de que outros personagens, fora do contexto ocidental, não são capazes de produzir reflexões filosóficas, ou que não são protagonistas da história. 
Nesse sentido, a leitura dos textos de filosofia grega poderia ser melhor aproveitada em diálogo com textos de filosofia egípcia, ameríndia, chinesa, entre outras. Entretanto, a tese hegemônica é tão entranhada que a simples proposta a se considerar a produção filosófica de outros povos gera muita resistência no ambiente acadêmico (RAMOSE, 2011). Ao mesmo tempo, Ribeiro (2019, p. 30) salienta que a apresentação de pensadoras e pensadores negros é uma uma poderosa postura antirracista, porque "para pensar soluções para uma realidade precisamos tirá-la da invisibilidade".

Conscientes disso, após a análise dos materiais didáticos, apresentamos às alunas e alunos uma lista de pensadoras e pensadores negros e indígenas de diversas áreas do conhecimento, bem como temas em que as filosofias africanas e ameríndias poderiam ter sido apresentadas nos livros didáticos, tais como: a mitologia iorubá e a cosmologia de povos indígenas latino-americanos como expressão de sabedoria; Ptah Hotep, Amenotep, Imhotep e os griôs (contadores de história, rapsodos) como referências da filosofia antiga; a proposta do quilombismo de Abdias Nascimento como possibilidade de pensar a filosofia política, ao lado da República de Platão ou da Política de Aristóteles; o feminismo expresso por Angela Davis e bell hooks; a filosofia decolonial de Frantz Fanon e Davi Kopenawa Yanomami; a crítica da necropolítica proposta por Achille Mbembe; dentre outros.

Antes do fim da roda de conversa um dos alunos partilhou que já fazia esse exercício de procurar por protagonistas pretos nos próprios livros didáticos desde a sexta série do Ensino Fundamental. Sua fala, muito simples, permitiu-nos perceber a importância da visibilidade e da representatividade também no espaço curricular:

Eu já fazia esse exercício que fizemos hoje. Folheava os livros, procurando alguém que fosse parecido comigo, que tivesse os mesmos traços que eu [...] eu sempre achei que não haviam mesmo negros que tivessem produzido alguma coisa além de samba ou futebol, coisas do pensamento sabe, da ciência. Lá em casa eu já falei sobre isso umas vezes com minha mãe. Hoje vou falar com ela que tem todas essas pessoas aí que produziram coisas na área da ciência. (Aluno X).

Além dessa partilha, o mesmo aluno fez sua própria síntese sobre o conceito de epistemicídio, utilizando a linguagem contemporânea da informática.

Acho que todo mundo aqui sabe o que são algoritmos. Nas redes sociais é um tipo um programa que identifica os gostos do usuário e os amigos que a pessoa mais interage e elimina ou esconde todos os outros, com quem ela interage pouco e as notícias que não se parecem com aquelas que a pessoa sempre lê. Aí a pessoa vai vivendo numa bolha digital onde só tem gente igual a ela, que pensa como ela e notícias de coisas com as quais ela se identifica. Eu acho que o epistemicídio é exatamente isso: ele coloca na timeline dos brancos, só gente branca. E esconde todo mundo que pensa ou é diferente. (Aluno X).

A síntese proposta por esse aluno demonstra que o processo vivenciado o ajudou a refletir criticamente acerca dos reducionismos epistemicidas de uma educação majoritariamente colonizada pela cultura ocidental europeia e reconhecer a existência e atuação de pensadoras e pensadores que falam a partir de outros lugares existenciais, geopolíticos, corporais, sexuais, etc.

$\mathrm{Na}$ terceira roda de conversa, as alunas e alunos debateram em pequenos grupos como e quando a temática das relações étnico-raciais poderia ser trabalhada nas aulas e em outros momentos da vida escolar. Inicialmente consideraram importante destacar que a temática já é trabalhada em alguns momentos e mesmo em algumas disciplinas, afora o ensino de Filosofia.

Foram destacados os seguintes momentos em que se trabalham essas temáticas: na semana dos povos indígenas, no mês de abril; na semana da consciência negra, no mês de novembro; alguns temas de história da África, da América pré-colombiana e história regional, na disciplina de História; em pesquisas específicas, de natureza regional em diversas disciplinas, dentre outras. A recordação desses elementos demonstra que já existe uma preocupação pela temática e pelo combate ao racismo por parte de muitos 
professores e também por parte dos eventos e pesquisas realizados pelo Núcleo de Estudos Afro-brasileiro e Indígena (NEABI) local.

Além dos momentos e temáticas já trabalhadas na instituição, o grupo salientou que não seria interessante não acrescentar mais conteúdos ao currículo escolar, que por si mesmo já é bastante extenso, mas, conforme indicado pelas leituras feitas, seria mais produtivo oferecer uma perspectiva africana, indígena ou mesmo de outros povos (pluriversal) às temáticas que já são discutidas e trabalhadas atualmente. As temáticas mais específicas de cada universo cultural poderiam continuar sendo trabalhadas em momentos específicos do ano letivo, como já acontece no momento.

Por considerarem o caráter interdisciplinar das temáticas, sugeriram que assumíssemos como proposta o modelos dos projetos integradores, que poderiam ser realizados apenas em uma disciplina, mas aberto à possibilidade de trabalho conjunto de diversas disciplinas. O destaque dado a essa proposta ocorreu porque os alunos já tinham experiência nessa modalidade de ensino na instituição.

De fato, a metodologia dos projetos de ensino permite a realização da proposta de integração curricular, ao possibilitar o trabalho de diversas disciplinas em torno de um único tema gerador, ao mesmo tempo em que permite a unidade avaliativa e a aprendizagem não apenas dos conteúdos mas da prática da pesquisa e da produção de conhecimento em grupos de trabalho (BENDER, 2014).

As rodas de conversas foram vivenciadas como primeira etapa de um processo mais longo de pesquisa e produção coletiva de conhecimento assumidos a partir do reconhecimento e valorização pela reflexão filosófica produzida por pessoas pretas e indígenas. Ao assumir esses referenciais teóricos e partir dos alunos para a construção de propostas educacionais percorremos um caminho inverso à imposição colonial do pensamento, por acreditar que o antirracismo e a decolialidade são posturas assumidas que devem ser explicitamente vividas com práticas concretas.

\section{Considerações finais}

Neste artigo apresentamos as percepções de 15 alunas e alunos do Ensino Técnico Integrado ao Médio de uma instituição de Educação Profissional do estado de Rondônia acerca da pertinência do tema das relações étnico-raciais no contexto educacional em que estão inseridos.

É importante salientar que as rodas de conversa foram realizadas no segundo semestre do ano de 2019 e que talvez se fossem realizadas hoje o tema estivesse presente desde o início das reflexões, visto que, após o assassinato de George Floyd nos Estados Unidos, o tema têm ganhado destaque nas redes sociais e possibilitado a maior divulgação de notícias sobre casos de racismo no Brasil, agora desmascarado; e maior protagonismo de personagens negros na mídia como tentativa dos agentes de comunicação de desvencilhar a própria imagem de práticas discriminatórias.

Consideramos também que talvez há dez anos, anteriormente às leis de cotas raciais nos processos seletivos e concursos públicos seríamos facilmente levados a refletir também sobre a ausência de alunos e professores negros e indígenas do espaço escolar. Não que hoje se tenha alcançado um número ideal, especialmente do quadro docente, mas ao menos já foram dados passos significativos nessa direção, e no campus onde a pesquisa foi realizada especialmente, de modo que os alunos não destacaram explicitamente essa ausência no decorrer das rodas de conversa.

Convidados a refletir acerca da pertinência das relações étnico-raciais em seu processo formativo, as alunas e alunos não pensaram como uma temática separada de outros anseios que apresentam para a Educação: a integração curricular, a importância de conhecimentos significativos, que dialoguem com a vida cotidiana, dentre outros aspectos. Para elas e eles, assim como para nós, o antirracismo não pode ser apenas um anexo aos conteúdos trabalhados no decorrer do ano, ou em dias específicos, mas deve ser compreendido como opção explícita vivenciada cotidianamente.

O processo vivenciado com os alunos prosseguiu com a elaboração coletiva de uma metodologia de ensino de cárater participativo e antirracista e de uma coletânea de projetos de ensino que se partem da 
leitura e reflexão de textos de mulheres pretas ${ }^{2}$. Acreditamos, contudo, que a partilha das rodas de conversa como ponto de partida desse processo seja uma contribuição importante para todas e todos que buscam alternativas concretas aos modelos hegemônicos de práticas educativas vigentes.

\section{Referências}

ALMEIDA, Sílvio. O que é racismo estrutural? Belo Horizonte: Letramento, 2018.

ARANHA, Maria Lúcia. Filosofando: introdução à filosofia. São Paulo: Moderna, 2016.

ARROYO, Miguel. Outros Sujeitos, Outras Pedagogias. Petrópolis: Vozes, 2012.

BRASIL. Ministério da Educação. Parecer CNE/CP n 003/2004. Diretrizes Curriculares Nacionais para a Educação das Relações Étnico-Raciais e para o Ensino de História e Cultura Afro-Brasileira e Africana. Diário Oficial da União: seção 1, Brasília, DF, p. 19, 19 maio 2004. Disponível em: http://portal.mec.gov.br/dmdocuments/cnecp_003.pdf. Acesso em: 2 out. 2019.

BENDER, William. Aprendizagem baseada em projetos: educação diferenciada para o século XXI. Porto Alegre: Penso, 2014.

CHAUÍ, Marilena. Convite à Filosofia. São Paulo: Editora Ática, 2010.

COTRIM, Gilberto; FERNANDES, Mirna. Fundamentos de filosofia. São Paulo: Saraiva, 2016.

DAVIS, Angela. Mulheres, Cultura e Política. São Paulo: Boitempo, 2016.

FANON, Frantz. Pele negra, máscaras brancas. Salvador: EDUFBA, 2008.

FRIGOTTO, Gaudêncio; CIAVATTA, Maria; RAMOS, Marise. Ensino Médio Integrado: concepções e contradições. São Paulo: Cortez, 2005.

GALLO, Sílvio. Filosofia: experiência do pensamento. São Paulo: Scipione, 2014.

INSTITUTO BRASILEIRO DE GEOGRAFIA E ESTATÍSTICA (IBGE). Desigualdades Sociais por Cor ou Raça no Brasil. Estudos e Pesquisas: informação demográfica e socioeconômica, Rio de Janeiro, n. 41, ID 101681, 2019.

MALDONADO-TORRES, Nelson. A topologia do ser e a geopolítica do conhecimento: modernidade, império e colonialidade. In: SANTOS, Boaventura; MENEZES, Maria Paula. Epistemologias do Sul. São Paulo: Cortez, 2010. p. 313-339.

MELO, Marcia Cristina; CRUZ, Gilmar de Carvalho. Roda de Conversa: uma proposta metodológica para a construção de um espaço de diálogo no ensino médio. Imagens da Educação, Maringá, v. 4, n. 2, p. 31-39, 2014. Disponível em: http://periodicos.uem.br/ojs/index.php/ImagensEduc/article/view/22222. Acesso em: 2 jan. 2020.

MORAES, Francisco; KÜLLER, José Antônio. Currículos Integrados no ensino médio e na educação profissional: desafios, experiências e proposta. São Paulo: Editora SENAC, 2016.

MOURA, Adriana Ferro; LIMA, Marcia Gloria. A reinvenção da roda: um instrumento metodológico possível. Revista Temas em Educação, João Pessoa, v. 23, n. 1, p. 98-106, jan./jun. 2014. Disponível em: https://periodicos.ufpb.br/ojs/ index.php/rteo/article/view/18338. Acesso em: 2 jan. 2020.

NASCIMENTO, Abdias. O quilombismo: documentos de uma militância pan-africanista. São Paulo: Editora Perspectiva; Rio de Janeiro: IPEAFRO, 2019.

NOGUERA, Renato. O ensino de Filosofia e a lei 10.6339. Rio de Janeiro: Pallas, 2014.

RAMOSE, Mogobe. Sobre a legitimidade e o estudo da filosofia africana. Tradução de Dirce Eleonora Nigro Solis, Rafael Medina Lopes e Roberta Ribeiro Cassiano. Ensaios Filosóficos, Rio de Janeiro, v. 4, p. 6-25, out. 2011.

RIBEIRO, Djamila. Quem tem medo do feminismo negro? São Paulo: Companhia das Letras, 2018.

RIBEIRO, Djamila. Pequeno Manual Antirracista. São Paulo: Companhia das Letras, 2019.

SILVA, Ana Célia. A desconstrução da discriminação no livro didático. In: MUNANGA, Kabemguele. Superando o Racismo na Escola. Brasília:MEC/SECAD, 2005. p. 21-34.

SILVA, Elion Souza; OLIVEIRA, Ana Teresa. O Ensino Médio Integrado sob diferentes perspectivas para o Ensino de Matemática. Zetetiké, Campinas, v. 26, n. 2, p. 423-438, maio/ago. 2018.

2. Esses materiais estão disponíveis na página online criada como produto da pesquisa coletiva (http://pluriversoept.com). 
Percepções dos alunos acerca da diversidade étnico-racial...

SOUSA, Augusto Rodrigues de; FELZKE, Lediane Fani; OLIVEIRA, Alexandre de. Afroperspectividade e Integração na Educação Profissional e Tecnológica. In: OLIVEIRA, Alexandre de; BARBOSA, Xênia (org.). Diálogos Interdisciplinares em Educação Profissional. São Paulo: Alexa Cultural; Manaus: EDUA, 2019. p. 173-196.

Data de submissão: 16/08/2020

Data de aceite: 29/09/2020 